\title{
EDITORIAL
}

\section{Editorial: Botox for levator ani}

\author{
B. H. Gurland ${ }^{1} \cdot$ L. Neshatian ${ }^{2}$
}

Received: 16 March 2019 / Accepted: 26 March 2019 / Published online: 16 April 2019

(c) Springer Nature Switzerland AG 2019

There is a significant unmet need for management of pain in functional anorectal pain disorders and we applaud Dr. Ooijevaar and his coauthors for their report on this complex patient population [1]. The authors identified the subgroup of patients with hypertonic pelvic floor who were refractory to medical therapy and treated them with Botox injection therapy. They made an important delineation between patients who complained of anorectal pain and had normal levator examination and those with marked tenderness over the levators and hypertonia on digital rectal exam. The outcome of Botox therapy was good in $47 \%$, temporary in $20 \%$, and poor in $37 \%$. We are impressed by the authors' report of $47 \%$ "good" improvement. Botox targets muscle relaxation, decreases spasticity, and thus alleviates pain secondary to high muscle tone. Although in another noncontrolled study of patients with chronic anorectal pain symptoms improved after botulinum toxin injection in $55.5 \%$ of patients [2] the efficacy of Botox injection was not superior to placebo in a prospective double blind placebo-control study [3]. Nonetheless, pelvic floor physical and biofeedback therapy is the only evidence based therapy for chronic anorectal pain syndrome [4]

In our clinical practice, given the paucity of treatment options for chronic anorectal pain, and minimal morbidity with Botox injection, we incorporate Botox therapy into the algorithm for hypertonic anorectal pain when pelvic floor physical therapy is ineffective, and only in selected patients [5]. In our experience, a patient who reports perineal burning and diffuse rectal pain with an unremarkable anal examination, does not respond to Botox and is best treated with medical therapy, pain management, and sometimes nerve blocks if neuropathy is a potential diagnosis. These patients

B. H. Gurland

bgurland@stanford.edu

1 Department of General Surgery/Division of Colorectal Surgery, Stanford University, Palo Alto, CA, USA

2 Department of Gastroenterology, Stanford University, Palo Alto, CA, USA are evaluated and treated in a multidisciplinary pelvic health center with services such as gastroenterology, colorectal, pain management, physical therapy, urology and gynecology to address all facets of pelvic floor dysfunction. We would also add that stress is an important trigger for levator ani syndrome and symptoms of pain and obstructed defecation can wax and wane over time. Patients are counseled to learn stress management techniques, meditate, eat a healthy diet and exercise in addition to resuming physical therapy.

The authors were thorough in distinguishing between and articulating the difference between the two populations, providing readers with a framework for offering Botox to carefully selected individuals. We are intrigued by the authors' distinction between sphincter and levator hypertonia and how that guides injection therapy. In future studies we hope the authors will elaborate on their techniques to distinguish tonicity, report outcomes with validated pain scores, and collect data on the duration of symptom relief. Future prospective randomized trials are necessary to understand the efficacy, functional consequences, and clinical utility of Botox therapy in functional anorectal pain disorders. Utilizing ultrasound to guide injection as compared to the blind injection technique, also warrants further investigation.

Unfortunately, in the USA, Medicare does not currently recognize the diagnoses of anal spasm or levator ani syndrome for reimbursement for Botox therapy, thus making this relatively safe therapy out of reach for some patients. We appreciate that the authors have shared their experience and results in the literature to educate physicians and third party payers about this low risk option and we are hopeful that this study will encourage the approval of Botox for management of functional spastic gastrointestinal disorders.

\section{Compliance with ethical standards}

Conflict of interest The authors declare that they have no conflict of interest. 
Ethical approval This article does not contain any studies with human participants or animals performed by any of the authors.

Informed consent For this type of study formal consent is not required.

\section{References}

1. Ooijevaar RE, Felt-Bersma RJF, Han-Geurts IJ, van Reijn D, Vollebregt PF, Molenaa CBH (2019) Botox treatment in patients with chronic functional anorectal pain: experiences of a tertiary referral proctology clinic. Tech Coloproctol. https://doi. org/10.1007/s10151-019-01945-8 (Epub ahead of print)

2. Rao SSC, Paulson J, Mata M, Zimmerman B (2009) Clinical trial: effects of botulinum toxin on levator ani syndrome- a doubleblind, placebo-controlled study. Aliment Pharmacol Therapeut 29(9):985-991
3. Atkin GK, Suliman A, Vaizey CJ (2011) Patient characteristics and treatment outcome in functional anorectal pain. Dis Colon Rectum 54(7):870-875

4. Chiarioni G, Nardo A, Vantini I, Romito A, Whitehead W (2010) Biofeedback is superior to electrogalvanic stimulation and massage for treatment of levator ani syndrome. Gastroenterology 138(4):1321-1329

5. Bolshinsky V, Gurland B, Hull TH, Zutshi M (2018) Levator ani syndrome: transperineal botox injections. Tech Coloproctol 22:465-466. https://doi.org/10.1007/s10151-018-1801-6

Publisher's Note Springer Nature remains neutral with regard to jurisdictional claims in published maps and institutional affiliations. 